1 Bioprocessing and Biological Engineering

\title{
2 Improved Yield of rhEPO in CHO Cells with Synthetic 5' UTR
}

3

$4 \quad$ Alan Costello ${ }^{1}$, Nga T. Lao ${ }^{1}$, Niall Barron ${ }^{2,3 *} \&$ Martin Clynes ${ }^{1 *}$

$5 \quad *$ These authors contributed equally

6

$7 \quad{ }^{1}$ National Institute for Cellular Biotechnology, Dublin City University, Dublin, D09 NR58, Ireland.

$8 \quad{ }^{2}$ National Institute for Bioprocessing Research and Training, Dublin, A94 X099, Ireland.

$9 \quad{ }^{3}$ University College Dublin, Belfield, Dublin 4, D04 V1W8, Ireland.

10

11 Correspondence should be addressed to: Alan Costello, National Institute for Cellular 12 Biotechnology, Dublin City University, Glasnevin, Dublin 9, Ireland, e-mail. 13 alan.costello23@mail.dcu.ie, tel.+35317006246. 


\section{Abstract}

2 The impact of local structure on mRNA translation is not well-defined pertaining to the 5' UTR. Reports 3 suggest structural remodelling of the 5' UTR can significantly influence mRNA translation both in cis 4 and trans however a new layer of complexity has been applied to this model with the now known 5 reversible post-transcriptional chemical modification of RNA. $N^{6}$-methyladenosine $\left(\mathrm{m}^{6} \mathrm{~A}\right)$ is the most 6 abundant internal base modification in mammalian mRNA. It has been reported that mRNAs harbouring $7 \mathrm{~m}^{6} \mathrm{~A}$ motifs in their 5' UTR have improved translation efficiency. The present study evaluated the 8 addition of putative $\mathrm{m}^{6} \mathrm{~A}$ motifs to the 5' UTR of a model recombinant human therapeutic glycoprotein, 9 Erythropoietin (EPO), in a direct comparison with an A to T mutant and a no adenosine control. The $10 \mathrm{~m}^{6} \mathrm{~A}$ construct yielded significantly improved EPO titer in transient batch culture over no adenosine 11 and $\mathrm{m}^{6} \mathrm{~T}$ controls by 2.84 and 2.61 -fold respectively. This study highlights that refinement of transgene 12 RNA elements can yield significant improvements to protein titer.

13 Key words: $5^{\prime}$ UTR, $N^{6}$-methyladenosine, $\mathrm{m}^{6} \mathrm{~A}, \mathrm{CHO}$, Bioprocessing, Synthetic biology 
2 RNA forms complex secondary and tertiary structures with known examples of structure-directed function (Leppek et al., 2017). Predicting the impact of cis-regulatory sequences of non-coding scripts, such as un-translated regions (UTR), on mRNA translation in higher eukaryotes remains a challenge. Recent growing appreciation for functional heterogeneity between eukaryotic ribosomal complexes and its associated proteins (Simsek et al., 2017; Shi et al., 2017) coupled with evidence of mRNA-structureinfluenced translation raises the question: how much regulatory potential is owed to mRNA structure and structure-directed recruitment of RNA-binding protein (RBP) translation-driving factors? (Topisirovic et al., 2011; Pichon et al., 2012; Manning \& Cooper, 2016). For this reason, the structure of UTR sequence in transgene expression cassettes may offer "playgrounds" for synthetic engineering of transgene expression. Early studies to synthetically remodel the 5' un-translated region (UTR) of transgene mRNA (Kozak, 1986; Grens \& Scheffler, 1990) indicated highly-stable GC-rich secondary duplexes $(\Delta \mathrm{G}=-50 \mathrm{kcal} / \mathrm{mol})$ upstream of the initiation AUG triplet prevented scanning of the $40 \mathrm{~S}$ ribosome subunit leading to reduced protein yield. And complete removal 5' UTR sequence comes with the caveat of omitting known translational enhancer elements, impacting negatively on mRNA translation (Stein et al., 1998).

Reversible epigenetic modifications to both genomic DNA (Suzuki \& Bird, 2008) and histone proteins (StrahI \& Allis, 2000) have been known to influence gene expression and regulate cellular behaviour. Recent discovery of the intermediary member of the central dogma, RNA, having similar reversible chemical tuning has redefined how RNA metabolism is viewed (He, 2010; Fu et al., 2014). The most abundant internal mRNA modification in mammalian cells is $N^{6}$-methyladenosine $\left(\mathrm{m}^{6} \mathrm{~A}\right)$ (Wei et al., 1975). Transcriptome analysis of human cells and mouse tissue have revealed $\mathrm{m}^{6} \mathrm{~A}$ consensus motifs to be in the form of DRACH, $[\mathrm{D}=\mathrm{G} / \mathrm{A} / \mathrm{U}][\mathrm{R}=\mathrm{G}>\mathrm{A}] \mathrm{m}^{6} \mathrm{AC}[\mathrm{H}=\mathrm{U}>\mathrm{A}>\mathrm{C}] . \mathrm{m}^{6} \mathrm{~A}$ motifs are present in coding regions, 3' or 5' UTRs of mRNAs (Dominissini et al., 2012; Meyer et al, 2012) and in non-coding RNA (ncRNA) scripts (Wei et al., 1975) with enriched abundance at stop codons (Huang et al., 2018). This discovery of RNA chemical tuning adds a new layer of complexity to our understanding of how UTR sequence and structures can regulate mRNA translation.

In mammalian cells, $\mathrm{m}^{6} \mathrm{~A}$ is generated by a multicomponent methyltransferase "writer"-complex comprised of; METTL3, METTL14 and WTAP (Liu et al., 2014; Ping et al., 2014). This reaction is reversible with the "eraser" proteins FTO (Jia et al., 2011) and ALKBH5 (Zheng et al., 2013). Both writer and eraser modifications occur in the cell nucleus. The molecular mechanisms underpinning how $\mathrm{m}^{6} \mathrm{~A}$ motifs are recognised by different known $\mathrm{m}^{6} \mathrm{~A}$-RNA binding proteins (RBPs) and regulate $\mathrm{m}^{6} \mathrm{~A}$ RNA fate is still poorly understood. It has been reported that the stability of $\mathrm{m}^{6} \mathrm{~A}$-modified mRNA is under dynamic regulation by three cytoplasmic "reader" proteins of the YTH domain family, YTHDF1- 
site (Zhu et al., 2014) as an aromatic cage (Li et al., 2014). The $\mathrm{m}^{6} \mathrm{~A}$ reader YTHDF2 recognises $\mathrm{m}^{6} \mathrm{~A}$ marked mRNA and selectively reduces the stability of such messages (Wang et al., 2014). The mechanism by which YTHDF2 destabilises mRNA harbouring $\mathrm{m}^{6} \mathrm{~A}$ was revealed to be mediated by accelerated transcript deadenylation via the CCR4-NOT complex (Du et al., 2017). While YTHDF2 controls the turnover of $\mathrm{m}^{6} \mathrm{~A}$ containing mRNA, YTHDF1-mediates enhanced translational efficiency of $\mathrm{m}^{6} \mathrm{~A}$ containing scripts (Wang et al., 2015). This mechanism of epigenetic post-transcriptional control permits the cell to prioritise the protein synthesis of $\mathrm{m}^{6} \mathrm{~A}$ marked mRNAs. Contrary to the mRNA-decay-promoting action of YTHDF2, IGF2BPs 1-3 have been identified as a family of $\mathrm{m}^{6} \mathrm{~A}$ readers that promote target mRNA stability and translation (Huang et al., 2018). The consensus $\mathrm{m}^{6} \mathrm{~A}$ recognition motif differs slightly between YTHDF and IGF2BPs with the nucleotide at position -3 to the A being $\mathrm{A} / \mathrm{U}$ for YTHDF and $\mathrm{U} / \mathrm{C}$ for IGF2BP. This selective recognition of different $\mathrm{m}^{6} \mathrm{~A}-\mathrm{RBP}$ families adds to the complexity of post-transcriptional epigenetic regulation.

Independent studies have demonstrated that the presence of consensus putative $\mathrm{m}^{6} \mathrm{~A}$ motifs in the 5 , UTR of transgene mRNA significantly improves the transcript's translation efficiency in both capindependent (Meyer et al., 2015; Yang et al., 2017) and cap-dependent (Wang et al., 2015) manners in human cells. Moreover, the location of a single $\mathrm{m}^{6} \mathrm{~A}$ motif in the 5 ' UTR significantly impacts the mRNAs' translation with close-proximity to the gene start codon giving the highest protein production (Meyer et al., 2015). An understudied area in industrial biotechnology has been improving the protein coding potential of transgene mRNA in mammalian production hosts. While codon optimisation has improved the rate of elongation, selectively biasing the host to initiate transgene protein synthesis and or increase mRNA stability could significantly enhance recombinant protein yields.

\section{Materials and Methods}

\section{Plasmid construction and transcript analysis}

The human EPO open reading frame was synthesised (GenScript) with one of; a putative $\mathrm{m}^{6} \mathrm{~A}$ GGACTAAAGCGGACTTGT, $\mathrm{m}^{6} \mathrm{~T}$ - GGTCTAAAGCGGTCTTGT, or no adenosine control sequence - CGGTGCCGGTGC, taken from (Yang et al., 2017). These constructs were cloned into in a pcDNA-3.1 (+) Hygromycin (Invitrogen) backbone using HindIII and EcoRV sites. RNA secondary structure was predicted with RNAFold (http://rna.tbi.univie.ac.at/cgibin/RNAWebSuite/RNAfold.cgi). Tertiary RNA structure was predicted using RNAComposer (http://rnacomposer.cs.put.poznan.p1/) and sequence features highlighted using PyMOL V2.2.

\section{Cell culture and transfection}

CHO-K1 (ATCC) were grown in Balan CD Growth A (Irvine Scientific) with (2.52g L ${ }^{-1}$ ) polyvinyl alcohol (PVA), and sub-cultured every 72-96hrs. Cultures were maintained in a Climo-Shaker 
1 (Kühner), $37^{\circ} \mathrm{C}, 80 \%$ humidity and $5 \% \mathrm{CO}_{2}$ with routine seeding at $2 \times 10^{5}$ cells $\mathrm{mL}^{-1}$ in $50 \mathrm{~mL}$ spin tube

2 (TPP). Cell growth and viability was monitored using the Guava EasyCyte ViaCount programme

3 (Merck Millipore). Prior to transfection, cells were washed twice with CHO S SFM II (Gibco) and

4 seeded at $1 \times 10^{6}$ cells $\mathrm{mL}^{-1}$ in $2 \mathrm{~mL}$ of CHO S SFM II. Transfection was performed in accordance with

5 the MIRUS Transit $2 X$ protocol. In brief, a complex of a [1:2] ratio $\mu \mathrm{g}$ pDNA to $\mu \mathrm{L}$ transfection reagent

6 was formed in $100 \mu \mathrm{L}$ of pre-warmed, $37^{\circ} \mathrm{C}$, CHO S SFM II, for 30 mins. Transfection complexes were

7 then added to the cell suspension and incubated for $24 \mathrm{hrs}$. All transfections were done using a ratio of

$81 \mu \mathrm{g}$ of plasmid DNA per $1 \times 10^{6}$ cells. $24 \mathrm{hrs}$ post transfection the cultures were washed twice in Balan

9 CD Growth A with PVA and seeded at $3 \times 10^{5}$ cells $\mathrm{mL}^{-1}$ in triplicate $5 \mathrm{~mL}$ cultures.

\section{RNA isolation}

Transfected cells were harvested by centrifugation at $91 \mathrm{x}$ g for 5 minutes. Cell pellets were washed in phosphate buffered saline (PBS) and centrifuged again. Total RNA was isolated from $1-5 \times 10^{6}$ cells using $1 \mathrm{~mL}$ of Tri-reagent (Ambion) with no divergence from the manufacturer's protocol. RNA quantification and quality were evaluated by NanoDrop (Thermo Scientific). To remove contaminating plasmid DNA, RNA samples were treated with DNase I (Sigma Aldrich) as per manufacturer's protocol.

\section{qPCR}

Reverse transcription of total RNA was performed with the High Capacity cDNA Reverse Transcription Kit (Applied Biosystems) in accordance with the manufacture's protocol. RT-qPCR was performed on an AB7500 (Applied Biosystems) using Fast SYBR Green Master Mix (Applied Biosystems). The 2X SYBR master mix was combined with $20 \mathrm{ng}$ of cDNA, $200 \mathrm{nM}$ forward and reverse primers, and water made up to $20 \mu \mathrm{L}$ final reaction volume. Each biological replicate sample was run in technical triplicate wells. Primer sequences used are as follows; Gapdh FW - TGGCTACAGCAACAGAGTGG, Gapdh RV - GTGAGGGAGATGATCGGTGT, hEPO FW - ACTTGTCTCGAGATGGGGGT, hEPO RV AGGTACCTCTCCAGGACTCG, HYG RW - ATGCTCCGCATTGGTCTTGA, HYG RV ATTTGTGTACGCCCGACAGT. Relative quantification of PCR products was calculated using the ddCt method with Gapdh as an endogenous control and HYG as a control of transfection efficiency. Error was calculated as the standard deviation of three biological replicates.

\section{ELISA}

Secreted EPO was quantified by enzyme linked immunosorbent assay (ELISA) of cell culture supernatant. Culture supernatant was harvested by centrifugation of cell suspension at $91 \mathrm{x} g$ for 5 minutes. Nunc-Immuno ${ }^{\text {TM }}$ MicroWell ${ }^{\mathrm{TM}} 96$ well solid plates (M9410 Sigma-Aldrich) were coated with $100 \mu \mathrm{L}$ of capture antibody MAB-287 (R\&D Systems), diluted 1:500 in coating buffer (C3041-50CAP) (Sigma-Aldrich) for $2 \mathrm{hrs}$ at $4^{\circ} \mathrm{C}$. Plate washing consisted of $3 \times 100 \mu \mathrm{L}$ per well washes of ELISA wash buffer (T9039) (Sigma-Aldrich). Blocking was done for $1 \mathrm{hr}$ at room temperature with (T6789) 
Blocking Buffer (Sigma-Aldrich). Standards of recombinant human EPO (Cat no. 329871) (Merck Millipore) were diluted to range from 8000-0 $\mathrm{pg} \mathrm{mL}^{-1}$ in sample dilution buffer (T6789 $+0.05 \%$

3 Tween20) (Sigma-Aldrich). Samples were diluted to fall within the range of standard curve and $100 \mu \mathrm{L}$ 4 incubated on the plate at $37^{\circ} \mathrm{C}$ for $1 \mathrm{hr}$. Rabbit Immunoglobulin-HRP (P0448) (Dako, Agilent) diluted 1:2000 was used for detection, $100 \mu \mathrm{L}$ per well was incubated for $1 \mathrm{hr}$ at room temperature. $100 \mu \mathrm{L}$ of development solution; $1.2 \mathrm{~mL}$ of 3,3',5,5'-Tetramethylbenzidin at $1 \mathrm{mg} \mathrm{mL}^{-1}$ in DMSO, $2.4 \mu \mathrm{L} 30 \%$ (v/v) hydrogen peroxide and $10.8 \mathrm{~mL}$ Phosphate-Citrate buffer (P4809) (Merck), was added to each well and incubated for 30 minutes. The reaction was stopped by adding $100 \mu \mathrm{L} 0.18 \mathrm{M} \mathrm{H}_{2} \mathrm{SO}_{4}$ to each well. Protein concentration was determined by reading on a Multi-scan Go (Thermo Fischer Scientific) and samples concentrations quantified using linear regression of the standard curve. Analysis consisted of six technical replicates over three biological replicates.

\section{Results}

It has been previously reported that $\mathrm{m}^{6} \mathrm{~A}$ motifs are significantly enriched in known circRNAs (Yang et al., 2017). In their study, Yang et al., (2017) demonstrated dramatic increases in the translation efficiency of circular mRNAs containing $\mathrm{m}^{6} \mathrm{~A}$ motifs upstream of a reporter-gene start codon in direct comparison to an A to T mutant and to a no adenosine control (No A CTRL). To investigate the potential of $\mathrm{m}^{6} \mathrm{~A}$ motifs improving the production efficiency of recombinant protein therapeutics in $\mathrm{CHO}$ cells, we cloned three variants up-stream of a recombinant human Erythropoietin (rhEPO) open reading frame (Fig. 1).

The three transcript variants; No A - CTRL, $\mathrm{m}^{6} \mathrm{~T}$ and $\mathrm{m}^{6} \mathrm{~A}$ were assessed by transient batch performance in a CHO-K1 host. There was no significant difference in peak cell density between the transcript variants and un-transfected (CHO-K1) and transfection reagent only (vehicle) controls (Fig. 2a). Nor were there any deleterious effects on cell viability (Fig. 2b). Secreted EPO was monitored by ELISA of culture supernatant harvested at $48 \mathrm{hr}$ intervals. Cell specific productivity (Qp) was highest in the $\mathrm{m}^{6} \mathrm{~A}$ variant (Fig. 2c). The mean Qp of CHO-K1 cells was improved to $\left(9.31 \mathrm{pg}^{-1} \mathrm{cell}^{-1} \mathrm{day}^{-1}\right)$ with $\mathrm{m}^{6} \mathrm{~A}$ from $\left(3.84 \mathrm{pg} \mathrm{cell}^{-1} \mathrm{day}^{-1}\right)$ in the No A control $(\mathrm{p}=0.00048)$ and $\left(3.56 \mathrm{pg}\right.$ cell $^{-1}$ day $\left.^{-1}\right) \mathrm{m}^{6} \mathrm{~T}(\mathrm{p}=0.00019)$. Accordingly, mean EPO titer was improved significantly in the $\mathrm{m}^{6} \mathrm{~A}$ variant at all time points of analysis over both $\mathrm{m}^{6} \mathrm{~T}$ and No A controls (Fig. $2 \mathrm{~d}$ ). The $\mathrm{m}^{6} \mathrm{~A}$ construct increased the mean secreted EPO titer to $\left(13.6 \mu \mathrm{g} \mathrm{mL}^{-1}\right)$ from that of $\mathrm{m}^{6} \mathrm{~T}\left(5.5 \mu \mathrm{g} \mathrm{mL}^{-1}\right)(\mathrm{p}=0.000487)$ and No $\mathrm{A}\left(5.7 \mu \mathrm{g} \mathrm{mL}^{-1}\right)(\mathrm{p}=0.000185)$ at $48 \mathrm{hrs}$ into culture (Fig. 2d). Expression of EPO mRNA with the $\mathrm{m}^{6} \mathrm{~A}$ variant culminated in a final increase at 144 hrs of 2.61 -fold over $\mathrm{m}^{6} \mathrm{~T}(\mathrm{p}=0.0042)$ and 2.84-fold over the No A control $(\mathrm{p}=0.0029)$ (Fig. 2d). 
The exact function of $\mathrm{m}^{6} \mathrm{~A}$ in eukaryotic translation is not fully understood with independent reports describing its role in an mRNA's translation efficiency (Wang et al., 2015) and mRNA turnover or stability (Wang et al., 2014; Du et al., 2016; Huang et al., 2018). The vectors used in this study drive the expression of a resistance gene Hygromycin-B-phosphotransferase (HYG) under a PKG promoter. Relative quantification (RQ) of HYG mRNA was assessed at 48, 96 and 144hrs and normalized to that of the No A control at each time point with respect to the endogenous control Gapdh in all cases (Fig. 3a). There was no significant difference between any of the three constructs at any time point indicating similar transfection efficiencies in all cases (Fig. 3a). The relative EPO mRNA abundance was 4.14fold $\left(\mathrm{p}=1.39 \times 10^{-5}\right)$ and 4.99 -fold $\left(\mathrm{p}=1.09 \times 10^{-5}\right)$ higher with $\mathrm{m}^{6} \mathrm{~T}$ and $\mathrm{m}^{6} \mathrm{~A}$, respectively over the No A control construct at $48 \mathrm{hrs}$ (Fig. 3b). Relative to the No A control at each time point the $\mathrm{m}^{6} \mathrm{~T}$ transcript variant remained higher with a 4.16-fold $\left(\mathrm{p}=7.1 \times 10^{-5}\right)$ and 3.45-fold $\left(\mathrm{p}=1.76 \times 10^{-6}\right)$ increase in mRNA abundance at 96 and $144 \mathrm{hr}$ time points respectively (Fig. 3b). Similarly, EPO mRNA abundance in the $\mathrm{m}^{6} \mathrm{~A}$ variant remained higher than the No A control with a 3.43-fold $(\mathrm{p}=0.00027)$ and 3.84-fold $(\mathrm{p}=$ $1.46 \times 10^{-5}$ ) increase in mRNA abundance at 96 and $144 \mathrm{hr}$ time points respectively (Fig. 3b). With transient transfection transgene expression decreases over time with the dilution of plasmid DNA as cells divide. There was no significant difference in the rate of HYG mRNA abundance decreasing over time between constructs (Fig. 3c). The $\log _{2}$ fold decrease in EPO mRNA abundance showed a significantly different profile for the No A control, from $(-0.5941)$ to $(-0.015)$ with $\mathrm{m}^{6} \mathrm{~T}\left(\mathrm{p}=5.47 \times 10^{-6}\right)$ and $(-0.0487)$ with $\mathrm{m}^{6} \mathrm{~A}\left(\mathrm{p}=4.3 \times 10^{-5}\right)$ between 48 and $96 \mathrm{hrs}$ into culture and from $(-1.1084)$ in the No A control to (-0.5284) for $\mathrm{m}^{6} \mathrm{~T}$ and $(-0.4013) \mathrm{m}^{6} \mathrm{~A}$ variants, $\left(\mathrm{p}=1.29 \times 10^{-5}\right),\left(\mathrm{p}=7.923 \times 10^{-6}\right)$ respectively between 96 and 144 hrs (Fig. 3d).

The three transcript variants used in this study contain subtle sequence differences, yet the relative mRNA abundance and subsequent translation differed greatly. The secondary structure of all transcript variants was analysed using RNAFold (Fig. 4a). There was similar structure present in the $\mathrm{m}^{6} \mathrm{~T}$ and $\mathrm{m}^{6} \mathrm{~A}$ constructs, but these differed greatly from the distinct open structure of the No A control (Fig. 4a). RNAComposer was used to predict the tertiary structure of these differing structures. The open loop structed remained in the tertiary model of the No A control (Fig. 4b). Again, there was a highly similar appearance between the $\mathrm{m}^{6} \mathrm{~T}$ (Fig. 4c) and $\mathrm{m}^{6} \mathrm{~A}$ variants (Fig. 4d).

\section{Discussion}

We present herein an observation of significantly improved recombinant titer with modifications of the 5' UTR of transgene mRNA. Employing a putative $\mathrm{m}^{6} \mathrm{~A}$ motif previously reported to significantly improve the cap-independent translation of circular mRNAs (Yang et al., 2017) in human cell lines. Here we report it to have a similar effect on the translation of linear EPO mRNA in CHO-K1 cells with higher Qp (Fig. 2c) resulting in increased secreted EPO titer (Fig. 2d). In transient batch culture we 
observed no deleterious effects on peak cell density (Fig. 2a) or cell viability (Fig. 2b) associated with any of the three transcript variants. It would be interesting to see if this positive impact on product titer would hold through in stable mixed pools or clonal studies. Also, the sequence variants lack a consensus Kozak motif, which is known to enhance translation. Future work should incorporate the use of a Kozak sequence in the 5' UTR design. Simple addition of the Kozak motif may not be sufficient as the inclusion of extra nucleotides would disrupt the 5' UTR secondary structure.

Perhaps the most interesting finding was the dramatic increase in EPO mRNA transcript variants harbouring putative $\mathrm{m}^{6} \mathrm{~T}$ and $\mathrm{m}^{6} \mathrm{~A}$ motifs (Fig. 3b). Normalizing for transfection efficiency with HYG mRNA, the $\mathrm{m}^{6} \mathrm{~T}$ and $\mathrm{m}^{6} \mathrm{~A}$ EPO mRNA variants had relative increases in abundance in the order of 4.14 and 4.99-fold, respectively over the No A control (Fig. 3b). The rate of $\mathrm{m}^{6} \mathrm{~T}$ and $\mathrm{m}^{6} \mathrm{~A}$ mRNA loss with transient delivery was significantly reduced compared to that of the No A control (Fig. 3d). Given that the loss of HYG mRNA was similar in all cases (Fig. 3c) and that RNA methylation is said to occur post-transcriptionally (Fu et al., 2014), this suggests that the increase in mRNA abundance is due to enhanced stability rather than improved transcription. Analysing the 5' UTR secondary folding of the three transcript variants (Fig. 4) revealed a highly similar structure for both $\mathrm{m}^{6} \mathrm{~T}$ and $\mathrm{m}^{6} \mathrm{~A}$ but these two differ greatly from the No A control. Variable translation efficiencies between the $\mathrm{m}^{6} \mathrm{~A}$ and $\mathrm{m}^{6} \mathrm{~T}$ suggest that the differences can be attributed to the putative methylation of a single nucleotide substitution. Recent evidence by Liu et al., (2015) described the presence of $\mathrm{m}^{6} \mathrm{~A}$ conferred changes to mRNA secondary structure. Their data suggests that methylation and demethylation resulted in dynamic remodelling of local mRNA structures terming this "the $\mathrm{m}^{6} \mathrm{~A}$ switch" (Liu et al., 2015). Restructuring of the $\mathrm{m}^{6} \mathrm{~A}$ transcript variant to include methylation is not possible with current RNA folding software but this could explain the improved translation observed with the $\mathrm{m}^{6} \mathrm{~A}$ over the $\mathrm{m}^{6} \mathrm{~T}$ transcript variants. To date, apart from circularization of transcript mRNA (Wesselhoeft et al., 2018), efforts to improve the stability of linear transgene mRNA have yielded modest returns (Ferizi et al., 2015; Holtkamp et al., 2006). The $\mathrm{m}^{6} \mathrm{~A}$ motif used in this study contains a $\mathrm{U} / \mathrm{C}$ at the -3 position which was found to be an enriched motif from the consensus with IGF2BPs (Huang et al., 2018). As described by Huang et al., (2018), recognition of $\mathrm{m}^{6} \mathrm{~A}$ by IGF2BPs enhanced mRNA stability. This could be an explanation for why the putative $\mathrm{m}^{6} \mathrm{~A}$ mRNA in this study had such improved relative mRNA abundance. Although we must point out this may also stem from the highly stable hairpin structures formed in the $\mathrm{m}^{6} \mathrm{~T}(\Delta \mathrm{G}=$ 32.30) and $\mathrm{m}^{6} \mathrm{~A}(\Delta \mathrm{G}=-30.40)$ variants over that of the No A control $(\Delta \mathrm{G}=-17.90)$. It is probable this increased mRNA abundance is a combination of both for the $\mathrm{m}^{6} \mathrm{~A}$ variant and can be attributed to the highly stable hairpin in the $\mathrm{m}^{6} \mathrm{~T}$ script.

Reports of reversible $\mathrm{m}^{6} \mathrm{~A}$ writing, erasing and reading (Liu et al., 2014; Ping et al., 2014; Jia et al., 2011; Zheng et al., 2013; Wang et al., 2014; Huang et al., 2018) point to this mechanism of posttranscriptional regulation being highly tuneable. As of yet it has not been reported if $\mathrm{m}^{6} \mathrm{~A}$ writers, 
1 erasers and readers are dynamic between different stages of culture in $\mathrm{CHO}$ cells. If this is the case,

2 transgene mRNA encoding selective putative $\mathrm{m}^{6} \mathrm{~A}$ motifs could be conditionally translated under 3 defined culture stages. With a report of targeted epigenetic editing of genomic DNA using a dCas94 GCN4 peptide fusion (Morita et al., 2016) and newly reported ssRNA targeting CRISPR proteins, 5 Cas13b (Cox et al., 2017) the potential for targeted epigenetic regulation of transgene mRNA in 6 mammalian hosts could offer new components to the mammalian cell engineering toolbox.

7

\section{FUNDING}

9 This work was conducted under the financial support of Scientific Foundation of Ireland (SFI) grant numbers 10 [13/IA/1963] and [13/IA/1841]. 
Cox, D.B.T., Gootenberg, J.S., Abudayyeh, O.O., Franklin, B., Kellner, M.J., Joung, J. \& Zhang, F. 2017, "RNA editing with CRISPR-Cas13", Science (New York, N.Y.), vol. 358, no. 6366, pp. 1019-1027.

Dominissini, D., Moshitch-Moshkovitz, S., Schwartz, S., Salmon-Divon, M., Ungar, L., Osenberg, S., Cesarkas, K., JacobHirsch, J., Amariglio, N. \& Kupiec, M. 2012, "Topology of the human and mouse m 6 A RNA methylomes revealed by m 6 A-seq", Nature, vol. 485, no. 7397, pp. 201.

Du, H., Zhao, Y., He, J., Zhang, Y., Xi, H., Liu, M., Ma, J. \& Wu, L. 2016, "YTHDF2 destabilizes m 6 A-containing RNA through direct recruitment of the CCR4-NOT deadenylase complex", Nature communications, vol. 7, pp. 12626.

Ferizi, M., Leonhardt, C., Meggle, C., Aneja, M.K., Rudolph, C., Plank, C. \& Rädler, J.O. 2015, "Stability analysis of chemically modified mRNA using micropattern-based single-cell arrays", Lab on a Chip, vol. 15, no. 17, pp. 35613571.

Fu, Y., Dominissini, D., Rechavi, G. \& He, C. 2014, "Gene expression regulation mediated through reversible m6A RNA methylation", Nature Reviews Genetics, vol. 15, no. 5, pp. 293-306.

Grens, A. \& Scheffler, I.E. 1990, "The 5'- and 3'-untranslated regions of ornithine decarboxylase mRNA affect the translational efficiency", The Journal of biological chemistry, vol. 265, no. 20, pp. 11810-11816.

He, C. 2010, "Grand challenge commentary: RNA epigenetics?", Nature chemical biology, vol. 6, no. 12, pp. 863.

Holtkamp, S., Kreiter, S., Selmi, A., Simon, P., Koslowski, M., Huber, C., Tureci, O. \& Sahin, U. 2006, "Modification of antigen-encoding RNA increases stability, translational efficacy, and T-cell stimulatory capacity of dendritic cells", Blood, vol. 108, no. 13, pp. 4009-4017.

Huang, H., Weng, H., Sun, W., Qin, X., Shi, H., Wu, H., Zhao, B.S., Mesquita, A., Liu, C. \& Yuan, C.L. 2018, "Recognition of RNA N 6-methyladenosine by IGF2BP proteins enhances mRNA stability and translation", Nature cell biology, vol. 20 , no. 3 , pp. 285.

Jia, G., Fu, Y., Zhao, X., Dai, Q., Zheng, G., Yang, Y., Yi, C., Lindahl, T., Pan, T. \& Yang, Y. 2011, "N6-methyladenosine in nuclear RNA is a major substrate of the obesity-associated FTO", Nature chemical biology, vol. 7, no. 12, pp. 885.

Kozak, M. 1986, "Influences of mRNA secondary structure on initiation by eukaryotic ribosomes", Proceedings of the National Academy of Sciences of the United States of America, vol. 83, no. 9, pp. 2850-2854.

Leppek, K., Das, R. \& Barna, M. 2018, "Functional 5' UTR mRNA structures in eukaryotic translation regulation and how to find them", Nature Reviews Molecular Cell Biology, vol. 19, no. 3, pp. 158.

Li, F., Zhao, D., Wu, J. \& Shi, Y. 2014, "Structure of the YTH domain of human YTHDF2 in complex with an m 6 A mononucleotide reveals an aromatic cage for $\mathrm{m} 6$ A recognition", Cell research, vol. 24, no. 12, pp. 1490.

Liu, J., Yue, Y., Han, D., Wang, X., Fu, Y., Zhang, L., Jia, G., Yu, M., Lu, Z. \& Deng, X. 2014, "A METTL3-METTL14 complex mediates mammalian nuclear RNA N 6-adenosine methylation", Nature chemical biology, vol. 10, no. 2, pp. 93.

Liu, N., Dai, Q., Zheng, G., He, C., Parisien, M. \& Pan, T. 2015, "N 6-methyladenosine-dependent RNA structural switches regulate RNA-protein interactions", Nature, vol. 518, no. 7540, pp. 560.

Liu, Y., Beyer, A. \& Aebersold, R. 2016, "On the dependency of cellular protein levels on mRNA abundance", Cell, vol. 165, no. 3, pp. 535-550.

Manning, K.S. \& Cooper, T.A. 2017, "The roles of RNA processing in translating genotype to phenotype", Nature Reviews Molecular Cell Biology, vol. 18, no. 2, pp. 102.

Meyer, K.D., Patil, D.P., Zhou, J., Zinoviev, A., Skabkin, M.A., Elemento, O., Pestova, T.V., Qian, S. \& Jaffrey, S.R. 2015, "5' UTR m 6 A promotes cap-independent translation", Cell, vol. 163, no. 4, pp. 999-1010. 
Meyer, K.D., Saletore, Y., Zumbo, P., Elemento, O., Mason, C.E. \& Jaffrey, S.R. 2012, "Comprehensive analysis of mRNA methylation reveals enrichment in 3' UTRs and near stop codons", Cell, vol. 149, no. 7, pp. 1635-1646.

Morita, S., Noguchi, H., Horii, T., Nakabayashi, K., Kimura, M., Okamura, K., Sakai, A., Nakashima, H., Hata, K. \& Nakashima, K. 2016, "Targeted DNA demethylation in vivo using dCas9-peptide repeat and scFv-TET1 catalytic domain fusions", Nature biotechnology, vol. 34, no. 10, pp. 1060.

Pichon, X., A Wilson, L., Stoneley, M., Bastide, A., A King, H., Somers, J. \& E Willis, A. 2012, "RNA binding protein/RNA element interactions and the control of translation", Current Protein and Peptide Science, vol. 13, no. 4, pp. 294-304.

Ping, X., Sun, B., Wang, L., Xiao, W., Yang, X., Wang, W., Adhikari, S., Shi, Y., Lv, Y. \& Chen, Y. 2014, "Mammalian WTAP is a regulatory subunit of the RNA N6-methyladenosine methyltransferase", Cell research, vol. 24, no. 2, pp. 177.

Shi, Z., Fujii, K., Kovary, K.M., Genuth, N.R., Röst, H.L., Teruel, M.N. \& Barna, M. 2017, "Heterogeneous ribosomes preferentially translate distinct subpools of mRNAs genome-wide", Molecular cell, vol. 67, no. 1, pp. 71-83. e7.

Simsek, D., Tiu, G.C., Flynn, R.A., Byeon, G.W., Leppek, K., Xu, A.F., Chang, H.Y. \& Barna, M. 2017, "The mammalian ribo-interactome reveals ribosome functional diversity and heterogeneity", Cell, vol. 169, no. 6, pp. 1051-1065. e18.

Stein, I., Itin, A., Einat, P., Skaliter, R., Grossman, Z. \& Keshet, E. 1998, "Translation of vascular endothelial growth factor mRNA by internal ribosome entry: implications for translation under hypoxia", Molecular and cellular biology, vol. 18, no. 6, pp. 3112-3119.

Strahl, B.D. \& Allis, C.D. 2000, "The language of covalent histone modifications", Nature, vol. 403, no. 6765, pp. 41.

Suzuki, M.M. \& Bird, A. 2008, "DNA methylation landscapes: provocative insights from epigenomics", Nature Reviews Genetics, vol. 9, no. 6, pp. 465.

Topisirovic, I., Svitkin, Y.V., Sonenberg, N. \& Shatkin, A.J. 2011, "Cap and cap-binding proteins in the control of gene expression", Wiley Interdisciplinary Reviews: RNA, vol. 2, no. 2, pp. 277-298.

Wang, X., Lu, Z., Gomez, A., Hon, G.C., Yue, Y., Han, D., Fu, Y., Parisien, M., Dai, Q. \& Jia, G. 2014, "N 6-methyladenosinedependent regulation of messenger RNA stability", Nature, vol. 505, no. 7481, pp. 117.

Wang, X., Zhao, B.S., Roundtree, I.A., Lu, Z., Han, D., Ma, H., Weng, X., Chen, K., Shi, H. \& He, C. 2015, "N 6methyladenosine modulates messenger RNA translation efficiency", Cell, vol. 161, no. 6, pp. 1388-1399.

Wei, C., Gershowitz, A. \& Moss, B. 1975, "Methylated nucleotides block 5' terminus of HeLa cell messenger RNA", Cell, vol. 4, no. 4, pp. 379-386.

Wesselhoeft, R.A., Kowalski, P.S. \& Anderson, D.G. 2018, "Engineering circular RNA for potent and stable translation in eukaryotic cells", Nature communications, vol. 9, no. 1, pp. 2629.

Yang, Y., Fan, X., Mao, M., Song, X., Wu, P., Zhang, Y., Jin, Y., Yang, Y., Chen, L. \& Wang, Y. 2017, "Extensive translation of circular RNAs driven by N6-methyladenosine", Cell research, vol. 27, no. 5, pp. 626-641.

Zheng, G., Dahl, J.A., Niu, Y., Fedorcsak, P., Huang, C., Li, C.J., Vågbø, C.B., Shi, Y., Wang, W. \& Song, S. 2013, "ALKBH5 is a mammalian RNA demethylase that impacts RNA metabolism and mouse fertility", Molecular cell, vol. 49, no. 1, pp. 18-29.

Zhu, T., Roundtree, I.A., Wang, P., Wang, X., Wang, L., Sun, C., Tian, Y., Li, J., He, C. \& Xu, Y. 2014, "Crystal structure of the YTH domain of YTHDF2 reveals mechanism for recognition of N6-methyladenosine", Cell research, vol. 24, no. 12, pp. 1493. 


\section{Figure Legends}

2 Fig. 1 To investigate the effect of m6A on protein translation two putative m6A motifs (GGACT) were inserted upstream of the human EPO open reading frame. a An A to T mutant was also tested (m6T) and a no adenosine control (No A - CTRL). The sequence variants were cloned between HindIII and Xhol (underlined) in a pcDNA3.1(+) Hygromycin backbone. The sites of methylation are indicated by an asterisk and the EPO start codon highlighted in grey. b Nucleotide sequence of EPO used for evaluation of different 5' UTR sequences.

Fig. 2 CHO-K1 were transiently transfected with m6A motif variants and batch performance assessed. a Cell growth post transfection is displayed as viable cells per $\mathrm{mL}$ of culture. $\mathbf{b}$ The $\%$ viability of transfected cells during batch culture. c Cell specific productivity (Qp) of cells from $0-48 \mathrm{hr}$ of culture. d Secreted rhEPO titer $\left(\mu \mathrm{g} \mathrm{mL}^{-1}\right)$ of transcript variants was measured using supernatant harvested every $48 \mathrm{hr}$ of culture. The values are based on six technical replicates over three biological replicates represented as the mean with standard deviation. Statistical analysis was done using a homoscedastic student t-test, $(\mathrm{p} \leq 0.05 *, \mathrm{p} \leq 0.01 * *, \mathrm{p} \leq 0.001 * * *)$.

Fig. 3 qRT-PCR analysis of total RNA harvested from CHO-K1 cells transiently expressing one of the No $A, m^{6} \mathrm{~T}$ or $\mathrm{m}^{6} \mathrm{~A}$ EPO mRNA transcript variants was run. a Relative quantification (RQ) of Hygromycin (HYG) mRNA was used as a control of transfection efficiency. RQ was done using the No A control as a calibrator at each time point of analysis. $\mathbf{b}$ RQ of EPO mRNA expression for all three transcript variants was calculated with respect to the No A control at each time point of analysis. $\mathbf{c}$ The rate of HYG mRNA loss over time during transient batch was calculated by the $\log _{2}$ fold reduction in relative mRNA abundance at a time point with respect to the initial reading at $t=48 \mathrm{hrs}$. $\mathbf{d}$ The $\log _{2}$ fold reduction in EPO mRNA loss over transient batch culture. Values seen are the mean of three biological replicates with error calculated by standard deviation. Statistical analysis was done using a homoscedastic student t-test, $\left(\mathrm{p} \leq 0.05^{*}, \mathrm{p} \leq 0.01^{* *}, \mathrm{p} \leq 0.001 * * *\right)$.

Fig. 4 The 5' UTR secondary and tertiary structures of the three sequence variants was evaluated. a RNAFold predictions of the 5' UTR and full EPO open reading frame for each transcript variant. Regions differing in secondary structure are circled. In all cases the difference occurred between the 5, UTR and the first 50bp of the EPO open reading frame. The tertiary structure from the transcriptional start site through the first 50bp of the open reading frame was analysed using RNAComposer and PyMOL. b Tertiary structure of the No A CTRL 5' UTR. The EPO start codon is highlighted in hot pink and the first $50 \mathrm{bp}$ of the open reading frame light pink. c Tertiary structure of the $\mathrm{m}^{6} \mathrm{~T} 5^{5}$ UTR with $\mathrm{m}^{6} \mathrm{~T}$ motifs coloured blue. $\mathbf{d}$ Tertiary structure of the $\mathrm{m}^{6} \mathrm{~A}{ }^{5}$, UTR with putative $\mathrm{m}^{6} \mathrm{~A}$ sites coloured orange. 


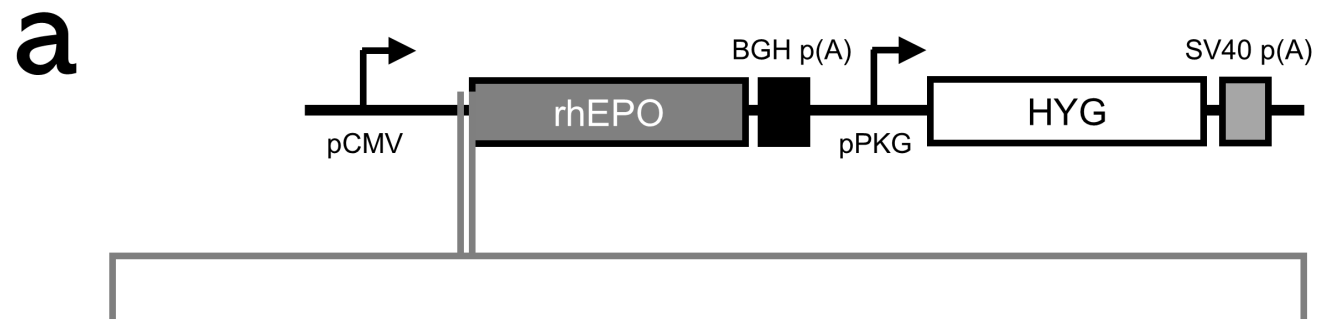

$>$ No A - CTRL

AAGCTTCGGTGCCGGTGCCTCGAGATG..

$>\mathrm{m}^{6} \mathrm{~T}$

AAGCTTGGTCTAAAGCGGTCTTGTCTCGAGATG..

$>\mathrm{m}^{6} \mathrm{~A}$

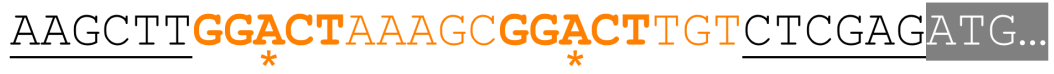

ATGGGGGTGCACGAATGTCCTGCCTGGCTGTGGCTTCTCCTGTCC CTGCTGTCGCTCCCTCTGGGCCTCCCAGTCCTGGGCGCCCCACCA CGCCTCATCTGTGACAGCCGAGTCCTGGAGAGGTACCTCTTGGAG GCCAAGGAGGCCGAGAATATCACGACGGGCTGTGCTGAACACTGC AGCTTGAATGAGAATATCACTGTCCCAGACACCAAAGTTAATTTC TATGCCTGGAAGAGGATGGAGGTCGGGCAGCAGGCCGTAGAAGTC TGGCAGGGCCTGGCCCTGCTGTCGGAAGCTGTCCTGCGGGGCCAG GCCCTGTTGGTCAACTCTTCCCAGCCGTGGGAGCCCCTGCAGCTG CATGTGGATAAAGCCGTCAGTGGCCTTCGCAGCCTCACCACTCTG CTTCGGGCTCTGGGAGCCCAGAAGGAAGCCATCTCCCCTCCCGAT GCGGCCTCAGCTGCTCCACTCCGAACAATCACTGCTGACACTTTC CGCAAACTCTTCCGAGTCTACTCCAATTTCCTCCGGGGAAAGCTG AAGCTGTACACAGGGGAGGCCTGCAGGACAGGGGACAGA $\underline{\text { TAA }}$ 
Figure 2

a

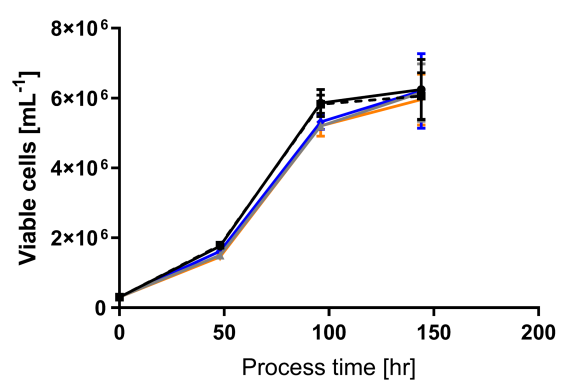

C

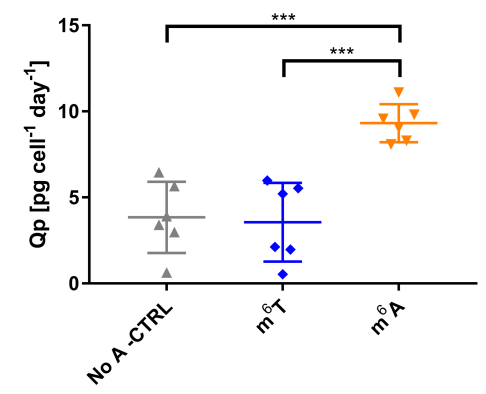

b

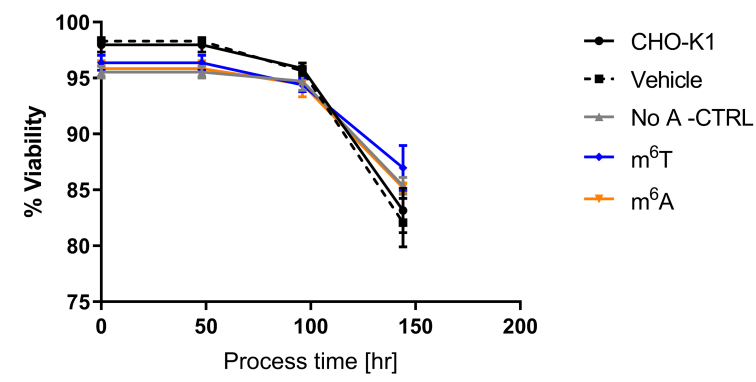

d

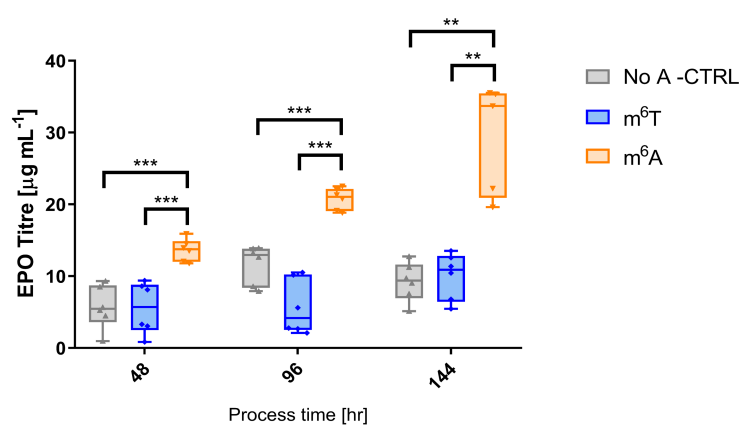


Figure 3

a

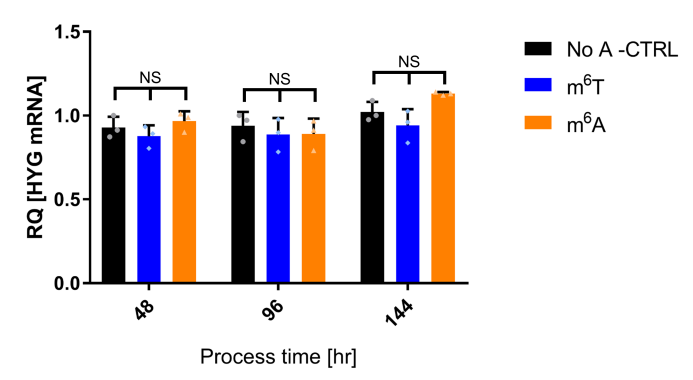

C

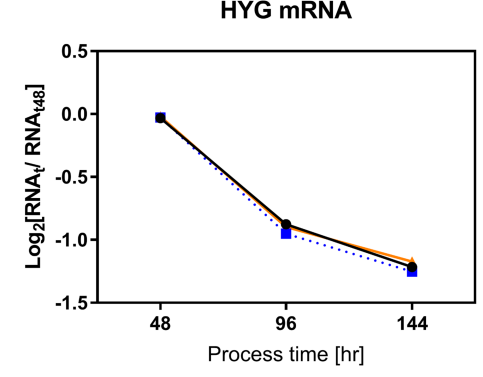

$\rightarrow$ No A -CTRL

-. $m^{6} T$

$-m^{6} \mathrm{~A}$

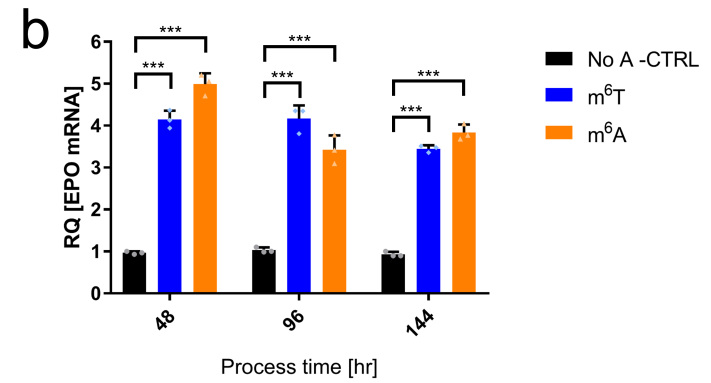

d

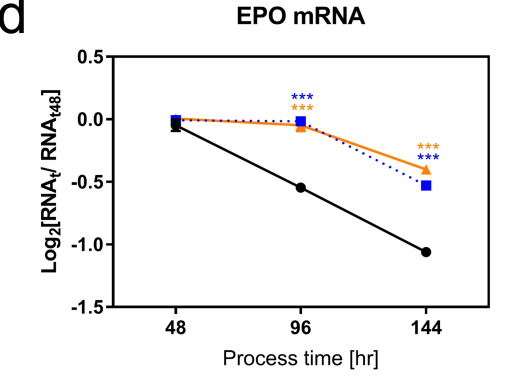

$\rightarrow$ No A-CTRL

-. $m^{6} \mathrm{~T}$

$-\mathrm{m}^{6} \mathrm{~A}$ 
$1 \quad$ Figure 4

a

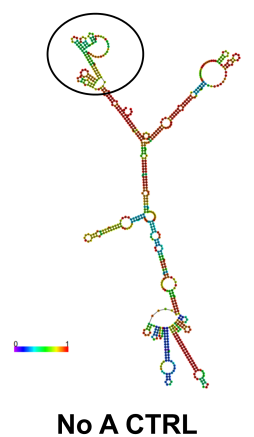

b

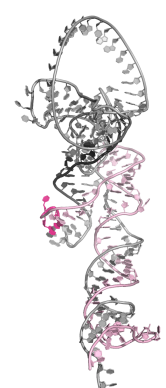

No A CTRL

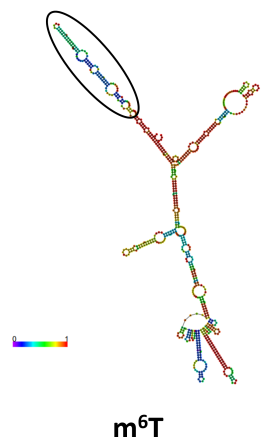

C

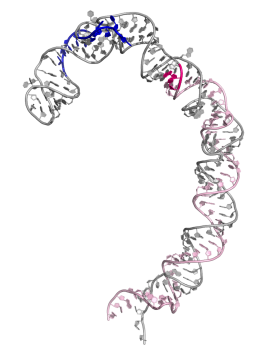

$\mathrm{m}^{6} \mathrm{~T}$

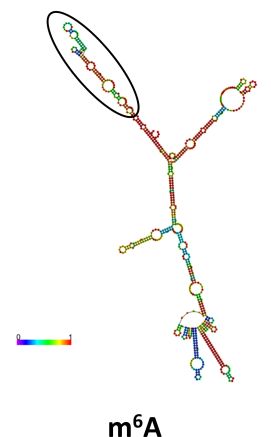

d

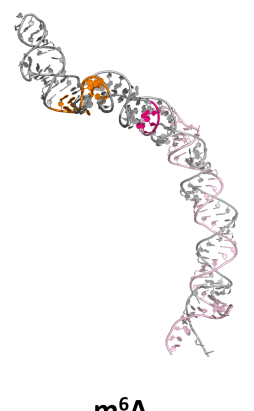

